standards that many organizations for blind people use to convert books and other published content to accessible formats. The DAISY standards are a set of specifications for formatting digital documents that allow for unrivalled speech-based access to texts. They permit blind people to easily navigate chunky textbooks, for example, to add audio notes, and to create and find bookmarks. The DAISY standards also make figures, graphics and equations machine-readable and thus accessible to the blind through a range of software and devices, including refreshable braille, embossing printers and tactile tablets.

"I'm very excited about EPUB 3," says Mark Doyle, director of journal information systems at the American Physical Society (APS) in New York. The APS is one of the few publishers to have experimented with using DAISY standards so far. Adding DAISY functionality to the society's papers would have been too cumbersome and costly, he says. But in the coming years it will be much easier to include it now that the APS is shifting its publishing workflow towards using EPUB 3 across the board.

However, whether publishers will take full advantage of the opportunities offered by EPUB 3 to make graphics and equations accessible remains a concern, says John Gardner, a solid-state physicist and founder of ViewPlus Technologies in Corvallis, Oregon. Gardner lost his sight at the age of 48 and has since dedicated his talents to developing assistive software and devices to make scientific content more accessible to the blind.

Even if publishers do widely embrace EPUB 3's accessibility features, another big unknown is whether e-readers and other devices will support them. Amazon's Kindle reader, for example, provides access to a vast library, including classics such as Molecular Biology of the Cell (5th edn, Garland Science, 2012), but is "still not fully accessible", says Danielsen.

Broader access came in May, when Amazon released an application that allows many Kindle e-books to be read on Apple devices using Apple's VoiceOver - a screen reader designed for the blind. Organizations for the blind give Apple products top marks for their attention to accessibility. Larry Hjelmeland, a blind researcher at the University of California, Davis, who studies the biology of eye ageing, says that Apple's latest operating system has made it much easier for him to read everything from e-mails to scientific papers.

Gardner hopes that the treaty and advances in technology will also help to address the under-representation of the visually impaired in science. "These people tend to have restricted opportunities for social interaction and entertainment," he says. "So they often are much more productive than people without disabilities." -

\title{
Imaging hits noise barrier
}

\section{Physical limits mean that electron microscopy may be nearing highest possible resolution.}

\section{BY EUGENIE SAMUEL REICH}

$\mathrm{P}$ lans for the next generation of electron microscopes have been dealt a blow by the discovery of an unexpected source of noise that could frustrate efforts to improve resolution to well below the size of an atom.

Researchers working for a leading manufacturer of advanced optics describe the noise source in a paper ${ }^{1}$ now in press. They think that they can find a way to mitigate it, but electron microscopists admit that the finding is the latest sign that their costly quest to capture ever more detailed images is coming up against physical limits. Some say their efforts might be better spent on making instruments cheaper and more widely available.

"Is it better to have ten machines working at 1-ångström resolution solving hundreds of materials-science problems, or one expensive instrument that may not work - but will push the boundaries?" asks David Muller, a physicist at Cornell University in Ithaca, New York.

Electron microscopes, first developed in the early twentieth century, fire electrons through a material and use the way they scatter to produce images thousands of times finer than can be captured with a light microscope. In 1959, US physicist Richard Feynman set a daunting challenge: to reach a resolution of $0.1 \AA$, smaller than the radius of an atom. Nearly 60 years later, in 2008, the US\$27-million Transmission Electron Aberration-Corrected Microscope (TEAM) project, at Lawrence Berkeley National Laboratory in Berkeley, California, unveiled a microscope with a resolution of $0.5 \AA$ - twice the sensitivity a microscope had achieved four years before, and the size of the smallest chemical bonds in nature. Since then, manufacturers have been pushing to make that technology more affordable, microscopists in Japan and Germany have planned their own sub-ångström instruments and the Berkeley researchers have sought even finer resolution for TEAM.

However, TEAM did not quite fulfil their hopes, despite reaching its intended resolution. The project's first instrument performed as expected, but a second failed to improve on its forebear, despite being more advanced.

The second microscope includes a chromatic-aberration corrector, a complex assembly



The German SALVE 2 electron microscope is being redesigned to limit noise.

of magnetic and electric lenses intended to remove blurriness caused by variations in electron energy. Researchers hoped that would help them to achieve a resolution of $0.33 \AA$, but the instrument turned out to have worse resolution than the first microscope. In 2010, engineers at Corrected Electron Optical Systems (CEOS) in Heidelberg, Germany, the company that built the roughly $€ 1.2$-million (US\$1.6-million) corrector, began to investigate why.

The answer was slow to come, says Stephan Uhlemann, a CEOS engineer. Eventually, in experiments this year, he found that he could replicate the blurring without the corrector, if he replaced it with empty tubes of materials used in its construction, such as a nickel-iron alloy, copper and stainless steel. This suggested that the noise arises from a physical phenomenon in the materials, rather than from problems with the lenses. The effect is worse at higher temperatures, so Uhlemann realized that it must be caused by thermal vibrations jiggling electrons in the materials and producing magnetic fields that jostle electrons in the microscope's beam ${ }^{1}$.

Such noise is thought to be present in all electron microscopes, but the scale of the CEOS 
> correctors - each nearly one metre long and weighing 0.75 tonnes - magnifies it. The company estimates that the effect limits resolution by $0.45-0.75 \AA$, enough to explain why the second TEAM microscope was unable to beat its forerunner.

"It's a physical limit, so we really have to think hard" about how to solve it, says Ute Kaiser, an electron microscopist at Ulm University in Germany who directs SubÅngström Low-Voltage Electron Microscopy (SALVE), a $€ 12$-million project to build two pioneering microscopes. SALVE and CEOS are working together to redesign one of these instruments, currently under construction, to try to reduce the noise problem by moving the electron beam farther away from the troublesome materials.

But magnetic effects are not the only source of noise identified in recent years. In 2012, Ruud Tromp, a microscopist at Leiden University in the Netherlands, and his colleagues showed that modern aberration correction is intrinsically unstable, and that electrostatic or other types of noise cause blurring after only a few minutes ${ }^{2}$. Muller's group has shown that at current resolution limits, quantum-mechanical effects from electrons scattering off atoms in crystals can make imaged atoms seem larger or smaller than they really are ${ }^{3}$.

Even with its current limits, the $0.5-\AA$ TEAM microscope can do groundbreaking science. In April, physicist John Miao and his group at the University of California, Los Angeles, published the first atomicscale images of crystal defects in a platinum nanoparticle ${ }^{4}$. Uli Dahmen, head of the US National Center for Electron Microscopy in Berkeley, where the microscope is housed, says that Miao's team is close to mapping nanoparticles in three dimensions. That would meet Feynman's ultimate goal of imaging materials atom-by-atom - even without achieving the resolution he called for. "I don't see anyone pressing materialsscience problems that can be solved at $0.3 \AA$ but can't be solved at $0.5 \AA$," says Dahmen. -

1. Uhlemann, S., Müller, H., Hartel, P., Zach, J. \& Haider, M. Phys. Rev. Lett. (in the press)

2. Schramm, S. M., van der Molen, S. J. \& Tromp, R. M. Phys. Rev. Lett. 109, 163901 (2012)

3. Hovden, R., Xin, H. L. \& Muller, D. A. Phys. Rev. B 86, 195415 (2012).

4. Chen, C.-C. et al. Nature 496, 74-77 (2013).

\section{BIOMEDICAL RESEARCH}

\section{Outcry over plans for 'Japanese NIH'}

\section{Researchers fear reforms will bring cuts to basic science.}

\section{BY ICHIKO FUYUNO}

$\mathrm{M}$ any people admire the US National Institutes of Health (NIH) as a model of how biomedical research should be funded. Japanese Prime Minister Shinzo Abe has taken that admiration a step further than most, with a plan to copy the NIH's structure. Much of the government's $¥ 320$ billion (US\$3 billion) in biological and biomedical research spending could come under the control of an institute that is set to start taking shape over the summer.

The plan, which came to light in mid-June with the publication of two government strategies, one on economic growth and one on health care, would mimic the centralized control of the NIH by consolidating management of research money for a range of research institutes (see 'All for one?'). But the plan also includes a goal to boost clinical applications, and many of the country's life-sciences societies fear that the institute would not emulate the part of the NIH that they most admire: its commitment to basic research.

"I feel at odds with the concept," says Noriko Osumi, a neuroscientist at Tohoku University in Sendai and president of the Molecular Biology Society of Japan. "It lacks respect for scientists' free-minded creativity, which is the foundation of the country's scientific strength."

The idea of a Japanese NIH had been under discussion for at least a decade before being backed by Abe. One of its champions is Yasuchika Hasegawa, chief executive of the Osaka-based Takeda Pharmaceutical Company - Japan's largest drug company - who sees inefficiencies in how Japan's biomedicalresearch cash is currently managed. Three ministries independently allocate research funds with little coordination, says Hasegawa. He has complained publicly that "walls between ministries" have hampered the translation of basic research into therapies.

"In other countries there are organizations that bridge the gap between academia and industry," Hasegawa noted at a press conference of the Japan Association of Corporate

\section{ALL FOR ONE?}

Japan has a range of separate major biomedical research institutes, but their budgets could soon be put under the control of a proposed Japanese National Institutes of Health.

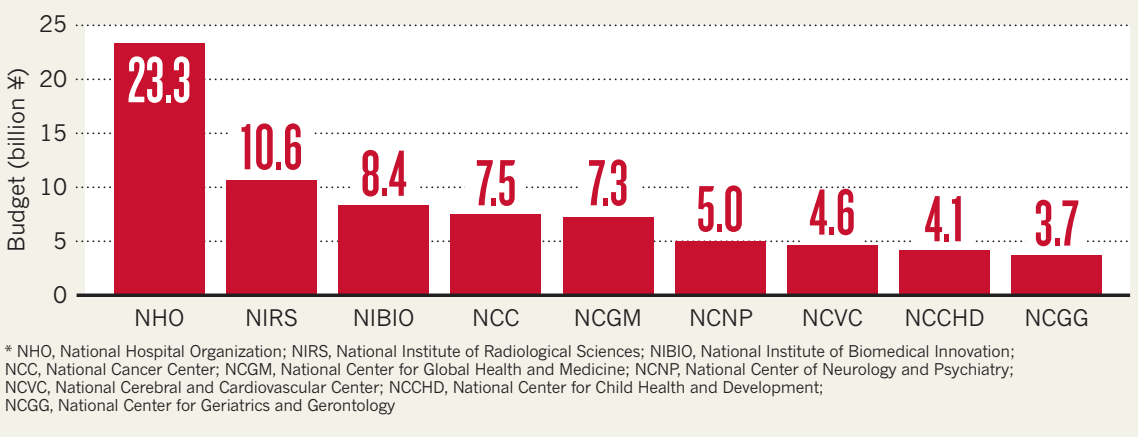

\section{TOP STORY}

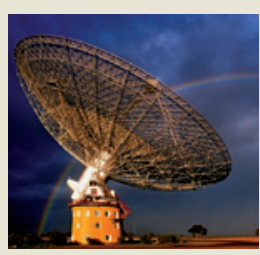

Extra-galactic radio bursts could help locate missing matter go.nature.com/ rfktzp

\section{MORE NEWS}

- Bid to protect Antarctic waters is back on agenda go.nature.com/uw1mpy - Spanish funding agency takes back unspent grants go.nature.com/6rjp8p - Crowdsourced instrument could open up ocean science go.nature.com/ w8y74c

\section{NATURE PODCAST}

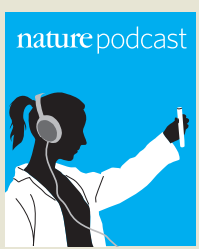

Water use in forests; nearextinctions disrupt ecosystems; and improving artificial speech nature.com/ nature/podcast 